\title{
HCA587 Antigen Expression in Normal Tissues and Cancers: Correlation with Tumor Differentiation in Hepatocellular Carcinoma
}

\author{
Bing Li, Xiao-Ping Qian, Xue-Wen Pang, Wan-Zhong Zou, Yu-Ping Wang, \\ Hong-Yan Wu, and Wei-Feng Chen \\ Departments of Immunology (BL, XPQ, XWP, HYW, WFC) and Pathology (WZZ, YPW), School of Basic Medical \\ Science, Peking University Health Science Center. Beijing 100083, China
}

SUMMARY: The HCA587 gene, identified by serological analysis of recombinant cDNA expression library (SEREX) from a hepatocellular carcinoma (HCC) patient, encodes a new member of cancer-testis antigens. HCA587 mRNA expression in normal tissues and cancers has been previously reported. To estimate its immunogenicity to induce immune response, it is essential to analyze HCA587 expression at the protein level. In this study anti-HCA587 polyclonal antibody, termed "TC-1," was generated, and the expression of HCA587 protein was assessed by immunohistochemical staining in a panel of normal and tumor tissue sections. No HCA587 protein was shown in normal tissues except germ cells in testis and Purkinji cells in cerebellum. In HCC specimens the HCA587 protein was expressed in 37.1\% (26 of 70) samples. The expressed protein was either located in the cytoplasm or nucleus depending on the individual samples. More importantly, there appears to be correlation between the tumor differentiation of HCC and HCA587 protein expression, ie, the lower differentiation, the higher percentage of protein expression. Coincidentally, seroreactivity showed that the Ab specific to recombinant HCA587 protein was detected only in the sera of three patients with poorly differentiated HCCs. HCA587 antigen was also expressed in different proportions in melanoma, lymphoma, pancreatic cancer, and lung cancer. (Lab Invest 2003, 83:1185-1192).

$$
T
$$
he recent advances of molecular technology for analyzing cellular and humoral immune response to cancer cells has led to the identification and characterization of a large number of human tumorassociated antigens recognized by $\mathrm{CD}^{+} \mathrm{T}$ cells and antibodies (Harashima et al, 2001; Ito et al, 2001; Shichijo et al, 1998). Most of these identified antigens belong to one of the following categories according to expression patterns or structural features: a) cancertestis (CT) antigens, such as the members of the MAGE gene family, SSX2, SCP1, and NY-ESO-1 (Old LJ, 2001); b) mutated antigens, eg, p53 (Theobald et al, 1995) and CDK4 (Rosenberg, 1997); c) overexpressed antigens, eg, HER-2/neu (Offringa et al, 2000) and PRAME (Ikeda et al, 1997); d) differentiation antigens, such as Melan-A/MART1, tyrosinase, and gp100 in melanocytes (Palermo et al, 2001); and e) virus antigens, such as hepatitis $B$ and $C$ viruses, in hepatocellular carcinoma (HCC) (Zondervan et al,

\footnotetext{
DOI: 10.1097/01.LAB.0000080605.73839.96

Received April 20, 2003.

This work was supported by grants from National 973 Program in China (No. G1999053904), Ludwig institute for Cancer Research (KSP003), National 863 program in China (No. 2001AA215411), and Beijing Municipal Government Foundation for Natural Sciences (No. 7001002). Address reprint requests to: Dr. Wei-Feng Chen, Department of Immunology, School of Basic Medical Science, Peking University Health Science Center, 38 Xue Yuan Road, Beijing 100083, China. E-mail: wfchen@public.bta.net.cn
}

2000), and human papilloma virus in cervical cancer (Sellors et al, 2003). Because of their characteristic expression patterns in cancer and testis, not in other normal tissues, CT antigens are of major interest as targets for immunotherapy and may also serve as tools for diagnostic purposes.

$\mathrm{HCC}$ is one of the most prevalent malignancies, with an increasing incidence worldwide, especially in East Asian countries (Okuda, 2000). In view of the poor prognosis for HCC patients with surgery and chemotherapies, an alternative of immuno- and genetherapeutic strategies has been pursued in patients to improve the treatment (Hanke et al, 2002; Reinisch et al, 2002). A prerequisite for the success of biotherapeutic strategies is the identification of the genes or antigens that are exclusively or preferentially expressed in malignant tissues. With the application of serological analysis of recombinant cDNA libraries (SEREX), several tumor-associated antigens have been identified in HCC by other groups (StennerLiewen et al, 2000; Wang et al, 2002) and our group. We have identified two novel CT antigens in HCC, one of which is HCA587. Investigating the immunogenicity of HCA587 will help us to understand if it is a potential target for immunotherapy and diagnosis in cancer patients.

By RT-PCR, we have demonstrated that HCA587 mRNA is highly expressed in HCC (Wang et al, 2002). However, we don't know the extent of HCA587 protein expression in HCC cells, and it is an essential condi- 
tion for the antigen to elicit immune response. In this study we have evaluated HCA587 protein expression in normal and malignant tissues by immunohistochemical (IHC) analysis using TC-1 polyclonal antibody (pAb) specific to the recombinant HCA587 protein. In addition a comparison was made between HCA587 mRNA expression and HCA587 protein expression in $\mathrm{HCC}$ specimens. The correlation between the percentage of HCA587 protein expression in HCC and the tumor differentiation of HCC was also estimated.

\section{Results}

\section{Production of Recombinant HCA587 Protein}

HCA587 entire open reading frame was subcloned into expression vector PQE30. Upon IPTG treatment the HCA587 protein, with a poly-histidine tail at $\mathrm{NH}_{2}$ terminus, was abundantly produced in Escherichia coli strain M15 (pREP4). Following purification on nickel columns, the purified HCA587 protein was reactive with anti-His mAbs (Qiagen, Chatsworth, California) in Western blot analysis, and the purity was $>90 \%$ by SDS-PAGE and gel scan.

\section{Generation of Anti-HCA587 pAb TC-1}

In ELISA assays the TC-1 reacted with the recombinant HCA587 protein at a titer of 1:10,000. To assess the reactivity of $\mathrm{TC}-1$ to the native protein expressed in tumor cells, lysates from several tumor cell lines, which express HCA587 mRNA, were analyzed by immunoblotting assays. Results showed that HCA587 protein was identified to be expressed in two melanoma cell lines (Mel-ed1 and Mel-kc) of HCA587 $\mathrm{mRNA}^{+}$, and there was no detectable HCA587 protein in two cell lines (HepG2 and 7721) of HCA587 mRNA ${ }^{-}$ or it was weakly expressed (Fig. 1). The TC-1 was hence able to detect naturally expressed HCA587 protein and was used in IHC analysis at a concentration of $0.5 \mu \mathrm{g} / \mathrm{ml}$.

\section{IHC Analysis}

HCA587 Protein Expression in Normal Tissues. Table 1 depicts the results of IHC staining of normal tissue with TC-1. Figure $2, A$ and $B$, shows the staining

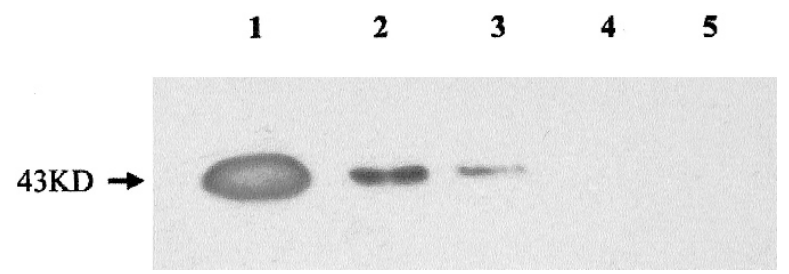

Figure 1.

Immunodetection of HCA587 gene product in cell lines and recombinant HCA587 protein as a positive control (Lane 1). Lysates from melanoma cell lines Mel-ed1 (Lane2), Mel-kc (Lane 3), HepG2 (Lane 4), and 7721 (Lane 5) were assayed using sodium dodecylsulfate-polyacrylamide gel electrophoresis and were assayed in immunoblotting with $\mathrm{TC}-1$, which recognizes protein exhibiting an apparent molecular weight of $43 \mathrm{kd}$.
Table 1. Immunohistochemical Staining of TC-1 in Normal Tissues

\begin{tabular}{lc}
\hline Histologic type & TC-1 \\
Cerebra & - \\
Cerebellum & + \\
Heart & - \\
Lung & - \\
Stomach & - \\
Skeletal muscle & - \\
Liver & - \\
Pancreas & - \\
Cholecyst & - \\
Small intestine & - \\
Ovary & - \\
Placenta & - \\
Spleen & - \\
Lymph node & - \\
Fatty tissue & - \\
Kidney & - \\
Prostate & - \\
Adrenal & - \\
Testis & ++ \\
\hline
\end{tabular}

cell types in testis. The testicular immunoreactivity was confined to the germ cells in the seminiferous tubules, and no immunoreactivity was present in the interstitial tissue and intertubular tissue components (Fig. 2A). The staining pattern of testis showed that the HCA587 protein was expressed in the nucleus as well as in the cytoplasm. Spermatogonia and primary spermatocytes showed strong intense staining. However, at the later stages of maturation, the staining intensity of spermatocytes became weak gradually, and matured spermatids were negative stained (Fig. 2B). In the 18 normal tissue samples of different organs stained by $\mathrm{IHC}$, besides testis, the Purkingji cells of the cerebellum were clearly stained (Fig. 2C) but not in other normal tissue samples. The positive staining of both tissues could still be seen when EDTA or citrate buffer was used as an antigen retrieval solution.

HCA587 Protein Expression in HCC. The expression of HCA587 protein in $70 \mathrm{HCC}$ samples is summarized in Table 2. The overall positive rate of HCA587 protein expression was $37.1 \%$ (26 of 70 ). Notably, the proportion of HCA587 protein expression was reversely correlated with the tumor differentiation of HCC. Higher frequency of HCA587 protein expression was seen in poorly differentiated HCC. The positive rate was $18.2 \%$ (4 of 22) in well-differentiated HCC, $32 \%$ (8 of 25 ) in moderately differentiated HCC, and $60.8 \%$ (14 of 23) in the poorly differentiated HCC. Among different HCC samples (Fig. 2, D to G), only the cancer cells were observed to be positive by $\mathrm{IHC}$ staining with TC-1. The staining intensity varied from weak to strong, and the staining pattern showed a high heterogeneity from focal (Fig. 2D) to more than $50 \%$ of the cancer cells (Fig. 2E). The location of the stained protein was from cytoplasm (Fig. 2F) to nucleus (Fig. 2G). 


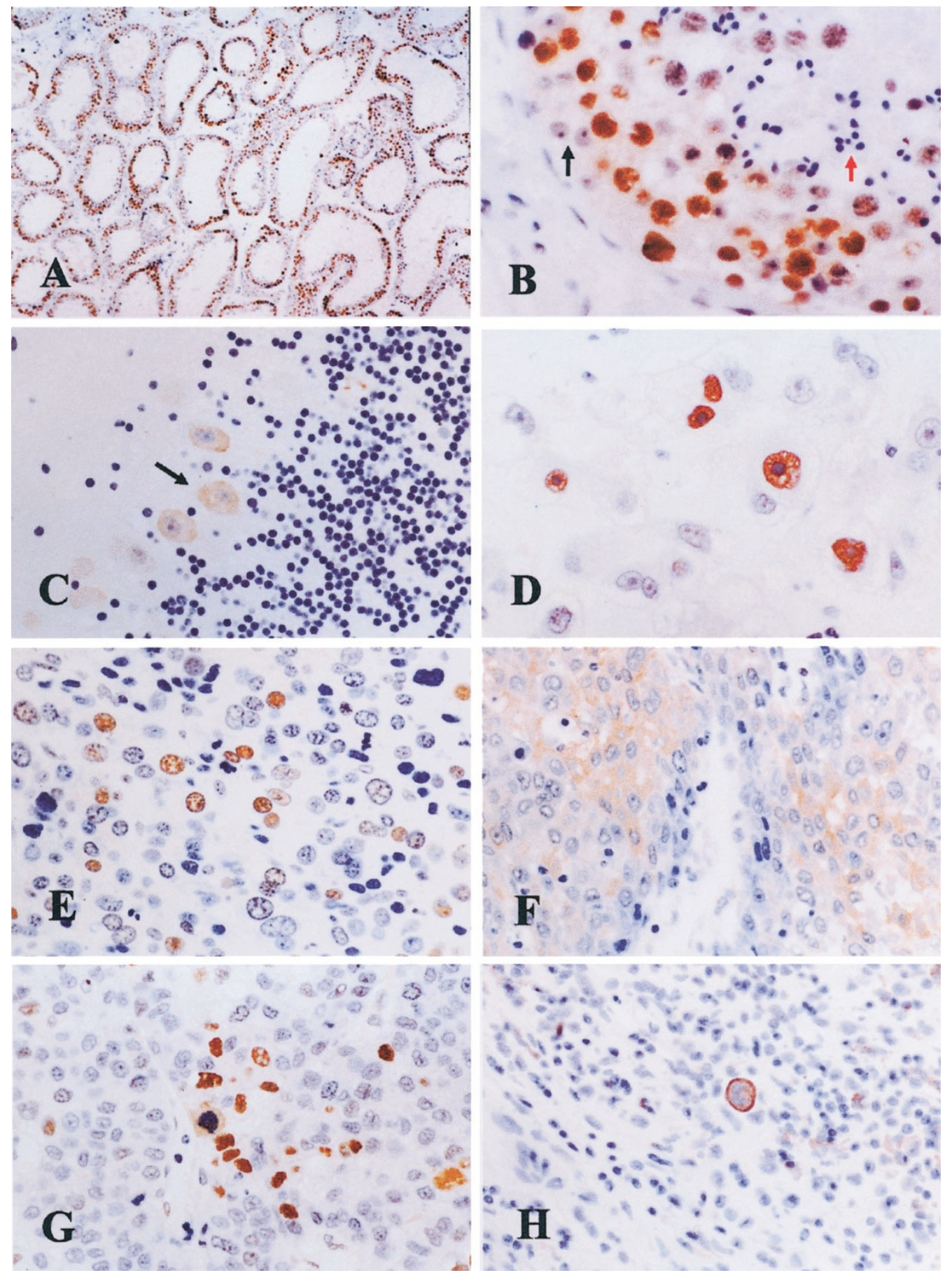

Figure 2.

Immunohistochemical staining of various tissue specimens with anti-HCA587 antibody TC-1 and with biotinylated antirabbit Ig G and the peroxidase-labeled avidin. The color was developed with DAB chromogen, and the slides were counterstained with hematoxylin. (A) Testis with extensive intratubular staining; the cells in interstitial tissue were negative. (B) Strong intense staining of spermatogonia and primary spermatocytes. Spermatids were negative (red arrow), and the Sertoli cells were also negative (solid arrow). (C) Positive staining with Purkinji cells in cerebellum (solid arrow). (D to G) Heterogeneous expression of HCA587 protein in HCC. (D) Focal nuclear staining in moderately differentiated HCC. (E) Nuclear staining in poorly differentiated HCC. (F) Cytoplasmic staining of HCA587 in well-differentiated HCC. (G) Obvious positive staining in the nucleus-dividing cancer cells. $(\mathrm{H})$ Immunoreactive positive cancer cells in metastatic melanoma.

HCA587 Protein Expression in Other Tumor Tissues. The expression of HCA587 protein in cancer panels other than HCC is shown in Table 3. The HCA587 protein-positive cells were more frequently shown in metastatic melanoma samples (3 of 6) (Fig. $2 \mathrm{H}$ ), and also observed in the minor proportion of lung cancer (non-small cell), mammary gland cancer, pancreatic cancer, and lymphoma. The HCA587 protein was expressed in seminoma, head and neck cancer, and ovarian cancer in the few samples examined. None of the $\mathrm{TC}-1$ reactive cells was seen in liposarcoma, renal cell carcinomas, colorectal tumors, or hemangioma. 
Table 2. HCA587 Expression in HCCs at mRNA Level and Protein Level

\begin{tabular}{|c|c|c|c|c|c|}
\hline \multirow[b]{2}{*}{ Histology ${ }^{a}$} & \multicolumn{2}{|c|}{ Protein expression } & \multicolumn{3}{|c|}{ mRNA and protein co-typing } \\
\hline & $\begin{array}{c}+ \text { ve/Total } \\
\text { (cases) }\end{array}$ & $\begin{array}{c}\text { Positivity } \\
(\%)\end{array}$ & $\mathrm{mRNA}^{+} / \mathrm{IHC}^{+}$ & $\mathrm{mRNA}^{+} / \mathrm{IHC}^{-}$ & $\mathrm{mRNA}^{-} / \mathrm{IHC}^{+}$ \\
\hline Well & $4 / 22$ & 18.2 & $1 / 6$ & $2 / 6$ & $0 / 6$ \\
\hline Moderately & $8 / 25$ & 32.0 & $2 / 9$ & $1 / 9$ & $0 / 9$ \\
\hline Poorly & $14 / 23$ & 60.8 & $4 / 5$ & $0 / 5$ & $0 / 5$ \\
\hline Total & $26 / 70$ & 37.1 & $7 / 20$ & $3 / 20$ & $0 / 20$ \\
\hline
\end{tabular}

HCC, hepatocellular carcinoma; IHC, immunohistochemistry.

${ }^{a}$ The difference of HCA587 protein expression in poorly differentiated HCC was statistically significant; $(p<0.05)$ compared with that in well- and moderately differentiated HCC

Table 3. HCA587 Expression in Tumor Panels: Immunohistochemical Staining with TC-1

\begin{tabular}{lc}
\hline Historical type & TC-1 (positive/total) \\
\hline Metastatic melanoma & $3 / 6$ \\
Lung (non-small cell) & $2 / 11$ \\
Mammary gland & $1 / 5$ \\
Pancreas & $2 / 11$ \\
Lymphoma & $2 / 10$ \\
Head and neck & $1 / 4$ \\
Ovary & $1 / 2$ \\
Seminoma & $1 / 2$ \\
Prostate & $0 / 10$ \\
Kidney & $0 / 3$ \\
Liposarcoma & $0 / 3$ \\
Colon & $0 / 3$ \\
Urinary bladder & $0 / 3$ \\
Hemangioma & $0 / 1$ \\
\hline
\end{tabular}

Resembling those observed in HCC samples, IHC staining of these tumors revealed a generally heterogeneous expression pattern of HCA587 protein. Foci of strongly positive tumor cells were seen among large negative areas. The HCA587 protein expression was restricted to cancer cells in all histologic types of cancers examined; no immunoreactivity was found in the stromal components or in the surrounding normal tissues.

\section{Comparison of HCA587 Expression by RT-PCR and IHC Staining}

To confirm the specificity of HCA587 antibody TC-1, a comparison of HCA587 protein and HCA587 mRNA expression in HCC samples was done. The HCA587 mRNA expression was detected in 22 of 38 (55.3\%) tumor specimens, in which mRNA integrity was confirmed by G3PDH. The expected PCR products of 1.2-kb HCA587 and 452-bp of G3PDH in HCC were equaled to the products in testis (Fig. 3), and these products were further confirmed by DNA sequencing. In Table 2, 20 HCC samples were available for both mRNA and protein analysis in parallel. Of these, all seven cases expressing HCA 587 protein displayed by TC-1 staining were mRNA positive by RT-PCR; three cases were protein negative by IHC but mRNA positive by RT-PCR, but all three cases exhibited low

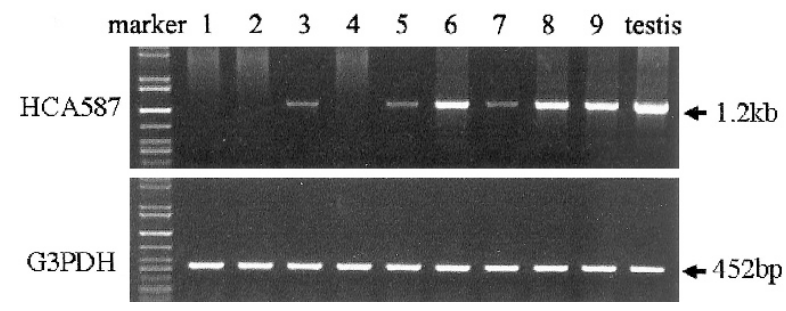

Figure 3.

Analysis of HCA587 mRNA expression in HCC tissue specimens. HCA587 mRNA expression assessed by RT-PCR from the samples of well-differentiated HCC (Lanes 1 to 3), moderately differentiated HCC (Lanes 4 to 6), and poorly differentiated HCC (Lanes 7 to 9).

copies of mRNA in the analysis of semi-quantitation of PCR products. None of the HCA587 mRNA-negative samples expressed HCA587 protein, indicating the specificity of IHC staining in HCC with HCA587 pAb TC-1.

\section{Seroreactivity Against HCA587 Protein in HCC Patients}

Sera from 82 patients with HCC were assayed for HCA587 Ig G antibody by ELISA using recombinant HCA587 antibody. Sera were tested at a 4-fold dilution from 1:100 to $1: 100,000$. HCA587 antibodies were only found in 3 of 82 patients. The Ab titer in these patients' serum was 1:1600, 1:6400, and 1:6400, respectively. Of note, all three seroreactive patients bore poorly differentiated HCC, and thus the seroreactivity was $8.6 \%$ (3 of 35 ) in the poorly differentiated $\mathrm{HCC}$ patients. No antibodies were detected in the sera of five healthy volunteers (Fig. 4).

\section{Discussion}

CT antigens are generally considered potential targets for immunotherapy in cancer patients due to their expression in a variety of human cancers but not in normal tissues, except testis (Boon and Old, 1997). Many promising results have been obtained in tumor immunotherapy using peptides derived from CT antigens (Marchand et al, 1999; Thurner et al, 1999). Because HCC is one of the most pernicious human cancers and the prognosis of HCC remains poor (Okuda, 2000), identification of CT antigens from HCC is definitely needed to find more tumor-associated 


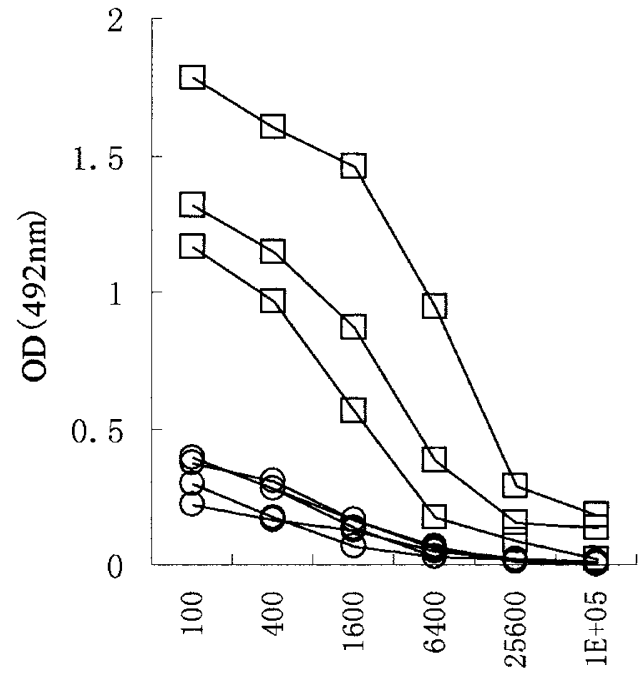

$1 /$ serum dilution

Figure 4

Seroreactivity of HCA587 protein in patients with poorly differentiated HCC. The serum Ab against HCA587 protein was measured by indirect ELISA using recombinant HCA587 protein as the antigen. The Ab titer was measured by the reaction of a series of 4 -fold dilution of sera with the antigen. The Ab titration from the sera of three patients with poorly differentiated HCC $(\square)$, and from the sera of five healthy volunteers (O) are shown.

antigens with good immunogenicity for effective immunotherapy.

HCA587 is a CT antigen that was identified using SEREX from HCC cDNA expression library by our group (Wang et al, 2002). The cDNA of HCA587 was cloned in 1999 (Genbank accession No. AF151378), with an identical sequence to MAGE-C2 (Lucas et al, 2000) and only two amino acids different than CT10 (Gure et al, 2000). The gene of HCA587, located in Xq27, belonged to the MAGE-C subfamily, with a large terminal exon encoding the 373aa entire protein. Because the first member of human MAGE families was identified as a gene-encoding tumor-specific antigen (van der Bruggen et al, 1991), these MAGE family antigens are of particular interest for antitumor immunotherapy because of their specific expression on tumor cells (Thurner et al, 1999). To assess HCA587 as a biomarker for diagnosis and immunotherapy, the actual HCA587 protein expression in cancer cells should be identified. For this aim we have produced pAb TC-1 specific to the recombinant HCA587 protein. The advantage of the pAb TC-1 is that it contains various types of Abs capable of binding different antigenic epitopes in the HCA587 protein. The specificity of TC-1 was proved by immunoblotting that it immunoprecipitated only with the recombinant HCA587 protein and the natural protein in lysates from HCA587 mRNA ${ }^{+}$cells lines Mel-ed1 and Mel-kc, but not with the lysates from HepG2 and 7721 of HCA587 $\mathrm{mRNA}^{-}$or was weakly expressed.

In the study of normal tissue staining with TC-1, testis showed strong immunoreactivity like that observed in the staining with anti-MAGE-1 antibodies (Takahashi et al, 1995). The HCA587 protein-positive cells were especially restricted to the spermatogonia and the primary spermatocytes. There was no TC-1 staining in postmeiotic cells or in testicular somatic cells (Satie et al, 2002). It is clear that the expression of HCA587 protein had decreased following the maturational process of spermatogenic cells and that protein expression had shut down in the sperm cells. This expression process also corresponded to the report using anti-MAGE-4 mAb (Itoh et al, 1996). Surprisingly, HCA587 protein was expressed in Purkingji cells in cerebellum shown in TC-1 staining using different antigen retrieval solutions. No other staining of normal tissues was observed in IHC analysis with TC-1.

In the series of HCC, direct comparison of RT-PCR analysis for mRNA and IHC staining with TC-1 confirmed the specificity of antibody TC-1 to HCA587 because no $\mathrm{mRNA}^{-} / \mathrm{IHC}^{+}$cases were observed. The higher rate of HCA587 mRNA expression than that of protein expression may be attributed to some low levels of HCA587 mRNA, which were unable to induce detectable protein by IHC. The IHC staining with $\mathrm{TC}-1$ reported here showed that expression of HCA587 antigen correlated with the differentiation degree of the HCC, with the preferential expression in poorly differentiated HCC. Similar results were also shown in NY-ESO-1 expression in melanoma (Goydos et al, 2001) and MAGE-A4 tumor antigen expression in transitional cell carcinoma (Kocher et al, 2002). A detailed reason is unclear. However, several studies have demonstrated that the expression of CT antigens appears to result from DNA demethylation (Desmet et al, 1999), and DNA demethylation is known to be associated with the de-differentiation process, which is likely to include events observed in advance stages of cancer development (Bernardino et al, 1997).

Among the available malignant tissues in our study, the highest HCA587 expression (50\%) was observed in metastatic melanoma, in which many other CT antigens were also highly expressed (Hofbauer et al, 1997). HCA587 was also expressed with a different ratio in the carcinomas of the lung, mammary gland, pancreas, head and neck, ovary, and seminoma. Our results of no TC-1 reactivity in colon, prostate, and renal cell carcinomas is consistent with a low frequency of CT antigens expression in these tumors reported by other researchers (Chen et al, 1997; Tureci et al, 1998). In the IHC staining of tumor tissue sections, the obvious feature of the staining pattern is the heterogeneous expression of HCA587 protein in tumor cells ranging from clusters to a large mass of tumor cells. Such heterogeneous expression of CT antigens are similar to that of other CT antigens, such as NY-ESO-1 (Satie et al, 2002), SSX (dos Santos et al, 2001), MAGE-1 (Zuber et al, 1997), and MAGE-3 (Fischer et al, 1997). Unlike the predominant expression of NY-ESO-1 antigen in the cytoplasm (SchultzThater et al, 2000), HCA587 antigen expression was found in the cytoplasm or nucleus.

Serological analysis of HCA587 protein showed that 3 of 82 HCC patients developed antibody responses without vaccine immunization, suggesting that HCA587 was immunogenic as it indeed elicited Th2 and $\mathrm{B}$ cell immune responses; this low rate of serore- 
activity was similar to some other members of the MAGE family. The MAGE-A1 antibody was seen on only 1 of 127 melanoma patients, and MAGE-A3 antibody was seen in 3 of 127 (Stockert et al, 1998). In the IHC staining, $37.1 \%$ of HCC patients expressed HCA587 protein, indicating that most of the HCC patients didn't form an antibody or they developed cellular but not humoral immunity against HCA587 because HCA587 protein was expressed in the cytoplasm or nucleus of cancer cells. In the present study, all three serological positive patients exhibited poorly differentiated HCC, in which stage higher percentage of HCA587 protein expression was observed by IHC staining.

Taken together, a pAb TC-1 with a high titer was elevated in a rabbit after it had been immunized with a purified HCA587 recombinant protein. TC-1 is reactive to both the recombinant protein and naturally expressed HCA587 antigen in cancer cells. The expression of HCA587 protein is conversely proportional to the differentiation degree of $\mathrm{HCC}$, and the overall HCA587 protein expression rate is around $37.1 \%$ in HCC samples, which constitutes about $70 \%$ of HCA587 mRNA ${ }^{+}$HCC samples. Therefore, HCA 587 is thought to be a valuable target antigen for diagnosis and vaccination of HCC patients. However, its expression in Purkingji cells in the cerebellum shows that the possibility of the vaccination damaging such cells and causing severe adverse effects should be highly considered.

\section{Materials and Methods}

\section{Preparation of HCA587 Recombinant Protein}

PCR-amplified HCA587 cDNA was directly cloned into pGEM-T-easy (Promega, Madison, Wisconsin). Clones were analyzed by restriction mapping, DNA sequenced, and subcloned into expression vector pQE30 (Qiagen, Valencia, California) with six-histidine tag on the $\mathrm{NH}_{2}$ terminus. Recombinant protein was induced by isopropyl $\beta$-D-thiogalactoside in $E$. coli and purified by $\mathrm{Ni}^{2+}$ affinity chromatography according to the procedure recommended by the manufacturer.

\section{Production of Anti-HCA587 Polyclonal Antibody}

Rabbits were immunized four times subcutaneously at 3 weeks intervals, with $100 \mu \mathrm{g}$ purified HCA587 recombinant protein in adjuvants. Complete Freund's adjuvant was used for the first-time immunization; in the subsequent immunizations, incomplete Freund's adjuvant (Sigma, St. Louis, Missouri) was used. Lysates of $E$. coli were used to absorb nonspecific antibodies against the residual $E$. coli components in the rabbit antiserum. The titer of rabbit antiserum was tested by solid-phase ELISA on microtiter plates coated with the immunizing recombinant HCA587 protein as a target antigen. The pAb of anti-HCA587 was purified by a protein A column (Pierce, Rockford, Illinois) to Ig G and termed "TC-1." To identify the specificity of TC-1, immunoblotting was performed using recombinant HCA587 protein and the lysates of several cells lines (Mel-ed1, Mel-kc, HepG2, and 7721), in which HCA587 mRNA expression had been assessed by RT-PCR.

\section{Tissue Sections}

Specimens consisting of formalin-fixed paraffinembedded tissue and optimal cutting temperature compound-mounted, snap-frozen tissue samples were collected from the Department of Pathology at the Peking University Health Science Center. Five- $\mu \mathrm{m}$ sections were cut from frozen and paraffin blocks and applied to histology slides for IHC staining. A panel of normal tissues (Table 1) and a series of malignant tissues of different histologic origins (Tables 2 and 3) were examined. The HCC tissue samples were also analyzed by RT-PCR to determine the HCA587 mRNA expression. Sera from 82 HCC patients were examined for serum antibody specific to the HCA587 protein.

\section{IHC Staining}

Sections were deparaffinized and rehydrated with xylene and a series grade of alcohol. Epitope retrieval was carried out in a 10-mm citrate buffer $(\mathrm{pH} 6.0)$ for 15 minutes at $95^{\circ} \mathrm{C}$ in a microwave cooker, followed by cooling for 30 minutes at room temperature (RT). After inactivation of endogenous peroxidase with $\mathrm{H}_{2} \mathrm{O}_{2}$, sections were blocked with $10 \%$ normal goat serum for 30 minutes and then incubated with anti-HCA587 $\mathrm{pAb}$ TC-1 for $4^{\circ} \mathrm{C}$ overnight. After washing, diluted biotinylated antirabbit Ig G (Zymed laboratories, Inc., South San Francisco, California) was added and further incubated for 20 minutes at RT. The slides were washed, and the peroxidase-labeled avidin (Zymed laboratories Inc.) was added and incubated for 20 minutes at RT. Diaminobenzidine tetrahydrochloride was then added as a chromogen, followed by counterstaining with hematoxylin solution. Sections of normal human testis were used as a positive control. An unrelated rabbit $\lg G$ at the same concentration was used as a negative control.

\section{RT-PCR}

To determine the specificity of antibody TC-1, HCA587 expression in HCC samples was compared by RT-PCR analysis and TC-1 IHC staining. RT-PCR was carried out as previously described (Wang et al, 2002). Briefly, total RNA was extracted from frozen tissue samples of HCC. Testicular tissue was used as a positive control tissue. RNA was reverse transcribed with AMV reverse transcriptase and oligodT ${ }_{(18)}$ (Clontech, Palo Alto, California). The quality of the cDNA was confirmed by PCR for G3PDH. Gene-specific PCR primers used to amplify HCA587 were designed according to our published sequences (HCA587 forward primer: 5'ATCGGATCCCCTCCCGTTCCAGGCGT 3', HCA587 reverse primer: 5'ACTAAGCTITCACTCAGAAAAGGAGAC3'). RT-PCR was performed with the Advantage Taq (Clontech) for 35 cycles in a 
GeneAmp PCR system 9700 (Applied Biosystems, Foster, California) at an annealing temperature of $60^{\circ} \mathrm{C}$. Products were analyzed on $1 \%$ agarose gels containing $0.01 \mathrm{mg} / \mathrm{ml}$ ethidium-bromide.

\section{ELISA}

Recombinant HCA587 protein at a concentration of 1 $\mu \mathrm{g} / \mathrm{ml}$ in coating buffer $\left(15 \mathrm{~mm} \mathrm{Na} \mathrm{CO}_{3} 30 \mathrm{~mm}\right.$ $\mathrm{NaHCO}_{3}, \mathrm{pH}$ 9.6) was absorbed to 96-well plates at $100 \mu \mathrm{l} /$ well overnight at $4^{\circ} \mathrm{C}$. Plates were washed with $0.05 \%$ Tween-20/PBS and blocked for 1 hour at RT with $100 \mu \mathrm{l} /$ well of $2 \%$ BSA/PBS. After washing, 100 $\mu \mathrm{l} /$ well of serum dilution in $2 \%$ BSA was added and incubated for 2 hours at RT. Plates were washed, and $100 \mu \mathrm{l} /$ well of the diluted (1:20,000) goat antihuman Ig G labeled with HRP secondary antibody (Promega, Madison, California) was added and incubated for 1 hour at RT. Plates were washed, and a substrate solution was added in each well, and then incubated for 10 minutes at RT. After adding $2 \mathrm{M} \mathrm{H}_{2} \mathrm{SO}_{4}$, the absorbance at $492 \mathrm{~nm}$ was measured using ELISA reader (Bio-Rad, Hercules, California). Sera were tested over a range of 4-fold dilution from 1:100 to $1: 100,000$.

\section{Statistical Analysis}

Statistical analysis was performed using $\chi^{2}$ test to study the relationship between the differentiation degree of HCC and HCA587 protein expression. Values of $p<0.05$ were considered statistically significant.

\section{References}

Bernardino J, Roux C, Almeida A, Vogt N, Gibaud A, Gerbault $\mathrm{SM}$, Magdelenat $\mathrm{H}$, Bourgeois $\mathrm{CA}$, Malfoy $\mathrm{B}$, and Dutrillaux $\mathrm{B}$ (1997). DNA hypomethylation in breast cancer: An independent parameter of tumor progression? Cancer Genet Cytogenet 97:83-89.

Boon T and Old LJ (1997). Cancer tumor antigens. Curr Opin Immunol 9:681-683.

Chen YT, Scanlan MJ, Sahin U, Tureci O, Gure AO, Tsang S, Williamson B, Stockert E, Pfreundschun M, and Old LJ (1997). A testicular antigen aberrantly expressed in human cancers detected by autologous antibody screening. Proc Natl Acad Sci USA 94:1914-1918.

Desmet C, Lurquin C, Lethe B, Martelange V, and Boon T (1999). DNA methylation is the primary silencing mechanism for a set of germ line- and tumor-specific genes with a CpG-rich promoter. Mol Cell Biol 19:7327-7335.

dos Santos NR, Torensma R, de Vries TJ, Schreurs MWJ, de Bruijn DR, Kater-Baats EK, Ruiter DJ, Adema GJ, van Muijen GN, and van Kessel AG (2001). Heterogeneous expression of the SSX cancer/testis antigens in human melanoma lesions and cell lines. Cancer Res 60:1654-1662.

Fischer C, Gudat F, Stulz P, Noppen C, Schaefer C, and Zajac P (1997). High expression of MAGE-3 protein in squamous-cell lung carcinomas. Int J Cancer 71:1119-1121.

Goydos JS, Patel M, and Shih W (2001). NY-ESO-1 and CTp11 expression may correlate with stage of progression in melanoma. J Surg Res 98:76-80.
Gure AO, Stockert E, Arden KC, Boyer AD, Viars CS, Scanlan MJ, Old LJ, and Chen YT (2000). CT10: A new CT antigen homologous to CT7 and the MAGE family, identified by representational difference analysis. Int $\mathrm{J}$ Cancer 85:726732.

Hanke P, Rabe C, Serwe M, Bohm S, Pagenstecher C, Sauerbruch T, and Caselmann WH (2002). Cirrhotic patients with or without hepatocellular carcinoma harbour AFPspecific T-lymphocytes that can be activated in vitro by human alpha-fetoprotein. Scand J Gastroenterol 37:949955.

Harashima N, Tanake K, Sasatomi T, Shimizu K, Miyagi Y, Yamada A, Tamura M, Yamana H, Ito K, and Shichijo S (2001). Recognition of the Lck tyrosine kinase as a tumor antigen by cytotoxic $T$ lymphocytes of cancer patients with distant metastates. Eur J Immunol 31:323-332.

Hofbauer GF, Schaefer C, Noppen C, Boni R, Kamarashev J, Nestle FO, Spagnoli GC, and Dummer R (1997). MAGE-3 immunoreactivity in formalin-fixed, paraffin-embedded primary and metastatic melanoma: $A$

frequency and distribution. Am J Pathol 151:1549-1553.

Ikeda $\mathrm{H}$, Lethe B, Lehmann F, van Baren N, Baurain JF, de Smet C, Chambost $\mathrm{H}$, Vitale M, Moretta A, Boon $T$, and Coulie PG (1997). Characterization of an antigen that is recognized on a melanoma showing partial HLA loss by CTL expressing an NK inhibitory receptor. Immunity 6:199-208.

Ito M, Shichijo S, Tsuda N, Ochi M, Harashima N, Saito N, and Ito K (2001). Molecular basis of T cell-mediated recognition of pancreatic cancer cells. Cancer Res 61:2038-2046.

Itoh K, Hayashi A, Nakao M, Hoshino T, Seki N, and Shichuo $S$ (1996). Human tumor rejection antigens MAGE. J Biochem 119:385-390.

Kocher T, Zheng M, Bolli M, Simon R, Forster T, Thater ES, Remmel E, Noppen C, Schmid U, Ackermann D, Mihatsch MJ, and Spagnoli GC (2002). Prognostic relevance of MAGE-A4 tumor antigen expression in transitional cell carcinoma of the urinary bladder: A tissue microarray study. Int $\mathrm{J}$ Cancer 100:702-705.

Lucas S, Plaen ED, and Boon T (2000). MAGE-B5, MAGE-B6, MAGE-C2, and MAGE-C3: Four new members of the MAGE family with tumor-specific expression. Int $\mathrm{J}$ Cancer 87:5560.

Marchand M, van Baren N, Weynants P, Brichard V, Dreno B, Tessier MH, Rankin E, Parmiani G, Arienti F, Humblet $Y$, Bourlond A, Vanwijck R, Lienard D, Beauduin M, Dietrich PY, Russo V, Kerger J, Masucci G, Jager E, De Greve J, Atzpodien J, Brasseur F, Coulie PG, van der Bruggen P, and Boon T (1999). Tumor regressions observed in patients with metastatic melanoma treated with an antigen peptide encoded by gene Mage- 3 and presented by HLA-A1. Int $\mathrm{J}$ Cancer 18:219-230.

Offringa R, van der Burg SH, Ossendorp F, Toes REM, and Melief CJM (2000). Design and evaluation of antigen-specific vaccination strategies against cancer. Curr Opin Immunol 12:576-582.

Okuda K (2000). Hepatocellular carcinoma. J Hepatol 32(Suppl 1):225-232.

Old LJ (2001). Cancer/testis(CT) antigens: A new link between gametogenesis and cancer. Cancer immunity 1:1-10.

Palermo B, Campanelli R, Garbelli S, Mantovani S, Lantelme E, Brazzelli V, Ardigo M, Borroni G, Martinetti M, Badulli C, 
Necker A, and Giachino C (2001). Specific cytotoxic T lymphocyte responses against Melan-A/MART1, tyrosinase and gp100 in vitiligo by the use of major histocompatibility complex/peptide tetramers: The role of cellular immunity in the etiopathogenesis of vitiligo. J Invest Dermatol 117:326332.

Reinisch W, Holub M, Katz A, Herneth A, Lichtenberger C, Schoniger-Hekele M, Waldhoer T, Oberhuber G, Ferenci $P$, Gangl A, and Mueller C (2002). Prospective pilot study of recombinant granulocyte-macrophage colony-stimulating factor and interferon-gamma in patients with inoperable hepatocellular carcinoma. J Immunother 25:489-499.

Rosenberg SA (1997). Cancer vaccines based on the identification of genes encoding cancer regression antigens. Immunol Today 19:175-182.

Satie AP, Meyts ERD, Spagnoli GC, Henno S, Olivo L, Jacobsen GK, and Samson M (2002). The cancer-testis gene, NY-ESO-1, is expressed in normal fetal and adult testis and in spermatocytic seminomas and testicular carcinoma in situ. Lab Invest 82:775-780.

Schultz-Thater E, Noppen C, Gudat F, Durmuller U, Zajac P, Kocher T, Heberer M, and Spagnoli GC (2000). NY-ESO-1 tumour associated antigen is a cytoplasmic protein detectable by specific monoclonal antibodies in cell lines and clinical specimens. Br J Cancer 83:204-208.

Sellors JW, Karwalajtys TL, Kaczorowski J, Mahony JB, Lytwyn A, Chong S, Sparrow J, and Lorincz A (2003). Incidence, clearance and predictors of human papilloma virus infection in women. CMAJ 168:421-425.

Shichijo S, Nakao M, Imai Y, Takasu H, Kawamoto M, Niiya F, Yang D, Toh Y, Yamana Y, and Itoh K (1998). A gene encoding antigenic peptides of human squamous cell carcinoma recognized by cytotoxic $\mathrm{T}$ lymphocytes. J Exp Med 187:277-288.

Stenner-Liewen F, Luo G, Sahin U, Tureci O, Koslovski M, Kautz I, Liewen H, and Pfreundschuh M (2000). Definition of tumor-associated antigens in hepatocellular carcinoma. Cancer Epidemiol Biomarkers Prev 9:285-290.

Stockert E, Jager E, Chen YT, Scanlan MJ, Gout I, Karbach J, Arand M, Knuth A, and Old LJ (1998). A survey of the humoral immune response of cancer patients of a panel of human tumor antigens. J Exp Med 187:1349-1354.
Takahashi K, Shichijo S, Noguchi M, Hirohata M, and Itoh K (1995). Identification of MAGE-1 and MAGE-4 proteins in spermatogonia and primary spermatocytes of testis. Cancer Res 55:3478-3482.

Theobald M, Biggs J, Dittmer D, Levine AJ, and Sherman LA (1995). Targeting p53 as a general tumor antigen. Proc Natl Acad Sci USA 92:11993-11997.

Thurner B, Haendle I, Roder C, Dieckmann D, Keikavoussi P, Jonuleit H, Bender A, Maczek C, Schreiner D, von den Driesch P, Brocker EB, Steinman RM, Enk A, Kampgen E, and Schuler G (1999). Vaccination with Mage-3A1 peptidepulsed mature, monocyte-derived dendritic cells expands specific cytotoxic $T$ cells and induced regression of some metastases in advanced stage IV melanoma. J Exp Med 190:1669-1678.

Tureci O, Chen YT, Sahin U, Gure AO, Zwich C, Villena C, Tsang S, Seitz G, Old LJ, and Pfreundschun M (1998). Expression of SSX genes in human tumors. Int $\mathrm{J}$ Cancer 77:19-23.

van der Bruggen $\mathrm{P}$, Traversari $\mathrm{C}$, Chomez $\mathrm{P}$, Lurquin $\mathrm{C}$, De Plaen E, van den Eynde B, Knuth A, and Boon T (1991). A gene encoding an antigen recognized by cytolytic $T$ lymphocytes on a human melanoma. Science 254:1643-1647.

Wang Y, Han KJ, Pang XW, Vaughan HA, Qu W, Dong XY, Peng JR, Zhao HT, Rui JA, Leng XS, Cebon J, Burgess AW, and Chen WF (2002). Large scale identification of human hepatocellular carcinoma-associated antigens by autoantibodies. J Immunol 169:1102-1109.

Zondervan PE, Wink J, Alers JC, IJzermans JN, Schalm SW, de Man RA, and van Dekken H (2000). Molecular cytogenetic evaluation of virus-associated and non-viral hepatocellular carcinoma: Analysis of 26 carcinomas and 12 concurrent dysplasias. J Pathol 192:207-215.

Zuber M, Spagnili GC, Kocher T, Luscher U, Schaefer C Noppen C, Gudat F, Harder F, and Heberer M (1997). Heterogeneity of melanoma antigen-1 (MAGE-1) gene and protein expression in malignant melanoma. Eur Surg Res 29:403-410. 